\title{
Investigating the evolution of fractures in clay-based ceramics during repeated freeze-thawing cycles using micro X-ray computed tomography and image analysis
}

Authors: Carlo Porfido ${ }^{1}$, Roberto Emanuele Rizzo ${ }^{2,3^{*}}$, David Healy ${ }^{3}$, Matteo Spagnuolo ${ }^{1}$, Roberto Terzano $^{1}$, Ignazio Allegretta ${ }^{1}$

${ }^{1}$ Dipartimento di Scienze del Suolo, della Pianta e degli Alimenti, Università degli Studi di Bari "Aldo Moro", Via Amendola 165/A, 70126, Bari, Italy; ${ }^{2}$ Institute of GeoEnergy Engineering, Lyell Centre, Heriot-Watt University Edinburgh, Research Avenue South, Edinburgh, EH14 4AS United Kingdom; ${ }^{3}$ School of Geosciences, King's College, University of Aberdeen, AB24 3UE United Kingdom

*Corresponding author: E-mail address: r.rizzo@hw.ac.uk; Tel: +44 (0) 7930093103; ORCID ID: $\underline{0000-0002-1607-6283}$

\begin{abstract}
This work presents a study on the fracturing behaviour of a quartz tempered clay-based ceramic subjected to damage in freeze-thaw cycles. X-ray micro-computed tomography (micro-CT) provided high-resolution imaging of the ceramic before and during the freeze-thaw treatment, allowing to analyse a fully water-saturated sample using a special thermal stage designed to keep the sample frozen during analyses. Micro-CT 3D renderings showed the internal features of the specimen (i.e., quartz grain distribution), the increment of fracture count and size, and the detachment of ceramic and/or temper fragments from the edges of the sample over the cycles. Selected 2D micrographs, before and after freeze-thawing treatment, were analysed using the MATLAB toolbox FracPaQ. This software provided detailed data on fracture length, intensity, density, orientation and connectivity, and enabled to interpret the process of fracture initiation and propagation inside the material. These results showed that the temper plays a crucial role in ceramic fracturing behaviour under freezethawing conditions, as damage propagation is influenced by quartz grain distribution and orientation within the material. The study described in this work, not only offers new insights into the fracture dynamics of freeze-thawed clay-based ceramics, but also presents a new methodological approach to quantitatively measure fracture damage in porous materials.
\end{abstract}

\section{Keywords}

Clay-based ceramics / X-ray micro computed tomography / Fractures / Freeze - Thawing / Image analysis

\section{Introduction}

Freeze-thaw weathering can affect both natural and artificial porous materials (e.g. soils, rocks, concrete, ceramics, etc.) and has a significant impact on their mechanical properties and durability. The effects of freeze-thaw cycling can be observed in different environments, leading for example to rock fracturing, influencing fluid flow in soils and rocks, favouring buildings decay or damage to 
architectural heritage and artifacts [1-4]. Fracturing in porous materials under freeze-thawing conditions has been investigated in the last decades and ice crystallization pressure has been identified as the main factor [5-8]. When water infiltrates into pores and fractures and solidifies into ice, it expands by up to $8.7 \%$ causing mechanical stresses and forcing the remainder liquid water in the surroundings of the pores. Once the hydraulic pressure exceeds the tensile strength of the material, fractures start to propagate. Small cracks can therefore evolve into larger fractures due to ice crystallization pressure, allowing further infiltration of the water inside the material after thawing. Alongside mechanical failure, freeze-thaw weathering can promote chemical degradation, i.e. carbonation and/or sulfation, as crack propagation can expose the material to salt crystallization. Hence, studying the evolution of fracture networks in freeze-thawing conditions is crucial as it can provide comprehensive information on the material strength and the related degradation processes.

Throughout history, clay-based ceramics have had, and still find, numerous applications for buildings and crafts, from bricks and tiles to water pipes and pottery $[9,10]$. Despite the extensive use of claybased ceramics, studies on the effects that freeze-thaw weathering on these materials are limited, although long-term exposure to the atmospheric environment can damage the ceramic materials, threatening buildings as well as sites and artefacts of historical importance [11-14]. Therefore, understanding and predicting ceramics fracturing behaviour is crucial for their preservation and conservation.

Currently, the analysis of fracturing in freeze-thawed samples is performed by means of various nondestructive techniques, such as acoustic emission, X-ray Computed Tomography (X-ray CT), ultrasonic pulse velocity, and resonant frequency [15-18]. Among these, micro X-ray computed tomography (micro-CT) is a powerful tool for the study of materials' microstructure and their changes after physical and/or chemical treatments, such as freeze-thawing [19-25]. Micro-CT allows twodimensional (2D) and three-dimensional (3D) sub-micrometre imaging of the sample and the pores; matrix, voids and inclusions can be distinguished and quantified via thresholding, according to their X-ray absorption behaviour. During freeze-thaw cycle treatments, X-ray micro-CT allows for the collection and comparison of sample data before and after treatment, thus highlighting the fracture network development. Usually, micro-CT applications to freeze-thaw experiments require the drying of the specimen before scanning, as the presence of water inside the sample may affect the accuracy in the tomography results [16-18]. However, drying a sample after a freeze-thaw treatment can lead to further modifications in the material structure; pores and fractures, once saturated with water and ice, become empty. This may cause a volume reduction resulting in the closure of some fractures, thus biasing the micro-CT data interpretation. Such limitation can be overcome by equipping the CT scanners with customized stages, which allow to control the temperature and to keep the sample frozen during the scanning [20].

In this work, we used a laboratory micro-CT apparatus equipped with a cooling stage to study the brittle deformation evolution in a clay-based ceramic sample during a series of freeze-thaw cycles. The cooling stage allowed us to scan the samples at $-20^{\circ} \mathrm{C}$ while fully water-saturated; thus, preventing ice-melting which may impact the quality of the acquisition and the data reliability. MicroCT renderings provided a comprehensive picture of the fractures and their evolution over ten freezethaw cycles, revealing structure distortion, fragmentation and detachments. Using the freely available MATLAB ${ }^{\mathrm{TM}}$-based toolbox, FracPaQ [26], it was possible to monitor and quantitatively assess the process of fracture propagation within the ceramic materials by quantifying the variations in fracture 
length, intensity, density, orientation and connectivity during the different freeze-thaw cycles. The application of non-destructive micro-CT acquisition techniques coupled with the analytical advantages offered by FracPaQ, make the proposed method readily applicable to the study of fracture evolution in other materials under a variety of deformation conditions.

\section{Material and methods}

\subsection{Sample}

Ceramic samples were prepared following the procedure reported in Allegretta et al. (2015) [27]. Briefly, a kaolin clay was mixed with 25 vol.\% of quartz temper (grain size of $1 \mathrm{~mm}$ ) and 5 vol.\% of water. The briquette was moulded by uniaxial pressure $(25 \mathrm{MPa})$, left drying at $100{ }^{\circ} \mathrm{C}$ for 24 hours and fired at $1000{ }^{\circ} \mathrm{C}$ using a heating rate of $150{ }^{\circ} \mathrm{C} / \mathrm{h}$ and a soaking time of $1 \mathrm{~h}$. Then, $5 \mathrm{~mm}$-side cubes were cut from the briquette and they were used as testing material.

Production of earthenware crafts (i.e. not glazed relatively coarse clay-based ceramics) dates back as early 29,000 - 20,000 BCE [28, 29]. The general formulation of traditional clay-based ceramics has not changed through the centuries and comprises a clay matrix (e.g. kaolin) and commonly calcite or quartz as mineral phases used for tempering [27]. The material used in this work mimics the formulation of archaeological and traditional clay-based ceramics, allowing us to generalise our finding to traditional and archaeological earthenware crafts.

\subsection{Experimental design}

The experiment was carried out as follows:

i. The dry ceramic specimen was initially analysed with micro-CT under ambient temperature conditions $\left(20^{\circ} \mathrm{C}\right)$ - Pre sample;

ii. The specimen was saturated with distilled water through complete immersion $(6 \mathrm{~h})$, then removed from the water and frozen overnight $\left(-20^{\circ} \mathrm{C}\right)$ in a freezer;

iii. The specimen was taken from the freezer and immediately transferred to the sample holder of the cooling stage of the micro-CT instrument, whose temperature was set at $-20^{\circ} \mathrm{C}$. CT analyses were carried out under constant controlled temperature $\left(-20^{\circ} \mathrm{C}\right)$;

iv. After the analysis, the specimen was warmed through immersion in distilled water (at ambient temperature) for 6 hours and then placed in the freezer overnight at $-20{ }^{\circ} \mathrm{C}$.

Steps ii, iii and iv were repeated ten times. Micro-CT analyses were performed after 3 (Post 3 sample), 7 (Post 7 sample) and 10 (Post 10 sample) freeze-thaw cycles. 


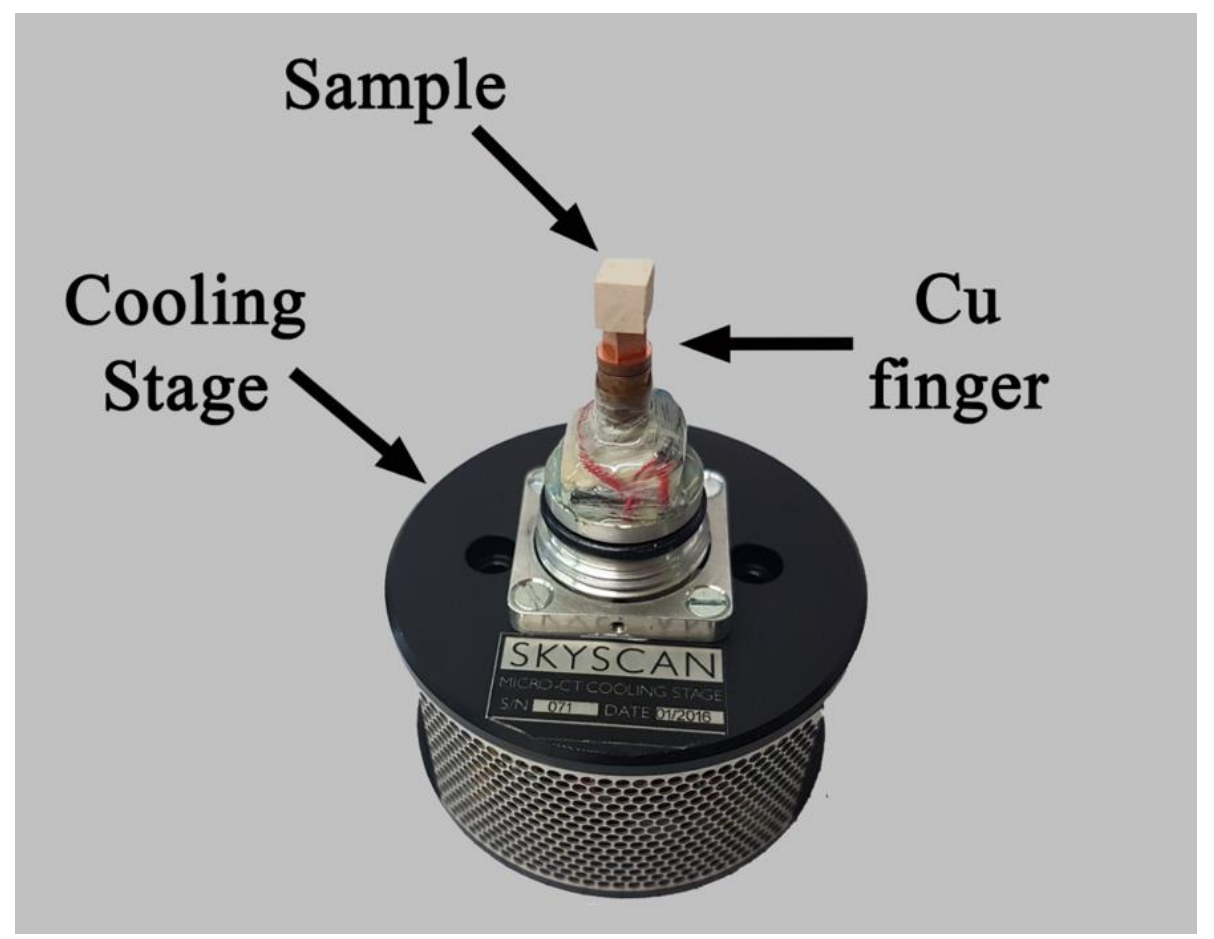

Figure 1 Supplementary The thermal stage and the analysed ceramic specimen

\subsection{Micro-CT analyses}

Micro-CT analyses were performed at the Micro X-ray Lab of the University of Bari, Italy. A SkyScan 1272 micro-CT instrument (Bruker Nano GmbH, Berlin, Germany) equipped with a W micro-focus source $(90 \mathrm{kV}, 111 \mu \mathrm{A},<5 \mu \mathrm{m}$ spot size) and a 16 mega-pixel CCD detector was used. A rotating cooling stage (CS) was employed instead of the conventional rotation stage of the instrument, to keep the temperature low and steady $\left(-20^{\circ} \mathrm{C}\right)$ during the scanning, thus preserving the frozen water infiltrating the specimen. In particular, after sample immersion in distilled water and overnight freezing at $-20^{\circ} \mathrm{C}$, the ceramic cube was immediately applied upon the "copper finger" of the CS (Fig. 1 Supplementary) by means of a drop of liquid distilled water, which rapidly and stably fixed the sample once frozen. Radiographies were acquired setting a pixel size of $2.0 \mu \mathrm{m}$, a rotation step of 0.2 degrees (from 0 to $180^{\circ}$ ) and an exposure time of $3400 \mathrm{~ms}$, for a total scan duration of $\sim 4 \mathrm{~h}$ : $23 \mathrm{~m}$. In order to improve data quality, flat field correction, averaging of 3 frames and random movement of 10 pixels were used during acquisition. Further, an $\mathrm{Al}-\mathrm{Cu}$ filter $(\mathrm{Al} 0.5+\mathrm{Cu} 0.038 \mathrm{~mm}$ thickness) was applied to improve the signal to noise ratio. A total of 949 angular projections were acquired and then reconstructed using the software NRecon version 1.6.10.4 that generated 2600slides stack of 4900 x 4900 pixels (pixel size $2.0 \mu \mathrm{m}$ ). Volumes' registration of Post 3, Post 7 and Post10 volumes was carried out with the software DataViewer (version 1.5.2.4, (c) Bruker $\mu-\mathrm{CT}$ ), using the Pre (initial dry ceramic) volume as reference. The software CTAnalyser (version 1.15.4.0 + , (c) Bruker $\mu$-CT) and CTvox (version 3.1.1 r1191, (c) Bruker $\mu-C T$ ) were used for measuring quantitative parameters and for the $3 \mathrm{D}$ rendering, respectively.

\subsection{Fracture Network Analysis}


To obtain information on the evolution of fracture attributes (i.e., length, orientation) and on their mutual geometrical relationships (i.e., density and connectivity of the fracture network) we used a freely available MATLAB ${ }^{\mathrm{TM}}$ software package called FracPaQ [26]. FracPaQ was designed to generate quantitative fracture pattern data, with user control over the outputs [26]. FracPaQ can quantify the length, orientation, connectivity, intensity and density of any 2D fracture pattern.

This software comprises a suite of tools that allow to consistently quantify fracture patterns and their variations in two-dimensions (2D). Fracture maps were produced by manually tracing all the fracture visible on 2D selected micrographs obtained through micro-CT, using the software Adobe Illustrator $^{\mathrm{TM}}$. Although time-consuming and potentially susceptible to some subjectivity [30], manual tracing allows the expert user to discern and identify specific features (e.g., discriminating fractures from pores and artefacts) which can be difficult to distinguish by an automated analysis [31, 32]. In order to avoid misinterpretations when tracing fractures onto the micro-CT image, we used threshold images as references. The aim of this approach is to minimize the users' interpretation biases while identifying fractures and, consequently, the errors in the final output.

Once the fracture trace map is created - and saved as a Scalable Vector Graphics (SVG) file - it is imported into FracPaQ. The software reads the SVG file extracting the $x-y$ coordinates of each fracture trace. The quantification of lengths and orientations is then reduced to simple operation in coordinate geometry [26]. In FracPaQ, a fracture trace is defined as a continuous line composed of one or more straight segments. The software assumes that fracture orientations (i.e. their strike) are measured clockwise for the positive Y-axis. From these inputs FracPaQ generates several diagrams (e.g., colour-coded maps for fracture and segment lengths) and plots (e.g. orientation distribution, histogram of lengths) which help to visualise areal distribution of fracture attributes in a material.

From the initial input data FracPaQ can also produce maps of fracture spatial arrangement. In particular, maps of fracture intensity, defined as the total length of fracture in a given area (here expressed in $\mathrm{mm}^{-1}$ ), and of fracture density, which is defined as the number of fractures per unit area (in $\mathrm{mm}^{-2}$ ), were created. Fracture intensity and density are estimated using the circular scan window method of Mauldon et al. [2001], applied to our coordinate geometry of fractures. The circle used to fit within a fracture trace map can be visualised on a separate diagram, and the user can adjust the number of circles fitting the map and their diameters. Fracture intensity is calculated as $n / 4 r$, where ' $n$ ' is the number of fractures intersecting the perimeter of the circle of radius ' $r$ '; fracture density instead is calculated as $m / 2 \pi^{2}$, where ' $m$ ' is the number of fractures terminating within the circle [3435].

Another important measurement FracPaQ can provide is fracture connectivity. This parameter is relevant to assess if a fluid (water in this case) can percolate throughout the whole material. The software draws a ternary plot of fracture connectivity [36] with the three vertices of the triangle denoting I, Y, X nodes in the fracture network. Nodes are classified as 'I' for isolated ends of fracture traces, ' $\mathrm{Y}$ ' for branching, splays or abutments and ' $\mathrm{X}$ ' for cross-cutting intersections. More connected networks plot towards the lower $\mathrm{Y}-\mathrm{X}$ tie of the diagram, whereas less connected networks plot towards the I apex. The relative proportions of I, Y and X nodes are then calculated with respect to the total number of intersections found. 


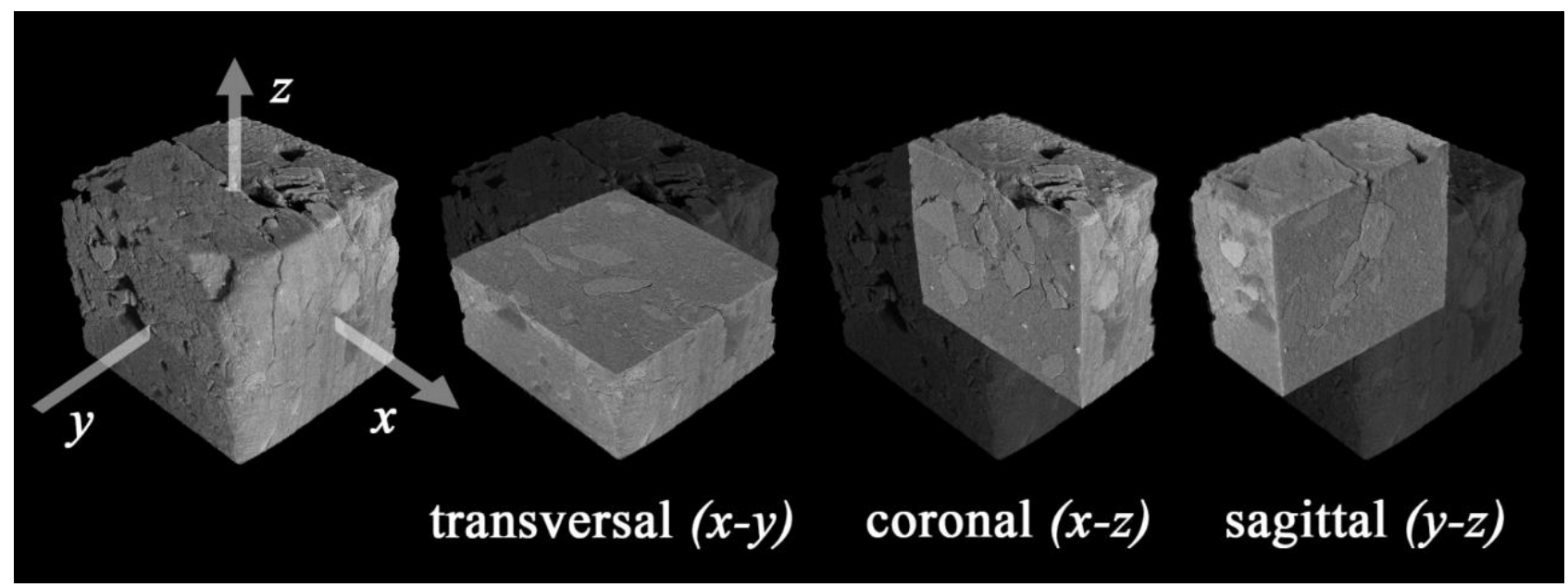

Figure 1 From left to right, 3-d rendering of the analysed ceramic specimen (Post 10) and visualization of the three selected sections for fracture analysis.

\section{Results and discussion}

\subsection{Micro-CT Analyses}

After micro-CT acquisition and datasets reconstruction and registration (full micro-CT 3D rendering is shown in Fig. 1), three mutually orthogonal planes passing through the centre of the ceramic specimen (i.e. transversal (X-Y), coronal (X-Z) and sagittal (Z-Y) planes) were chosen for investigating the fracture evolution over ten freeze-thaw cycles (Fig. 1). Figure 2 (see also Video 1) shows the transversal, coronal and sagittal sections of the untreated ceramic (Pre) and those after 3 (Post 3), 7 (Post7) and 10 (Post10) freeze-thaw cycles, for the same specimen. A preliminary overview of the greyscale micrographs (where grey values, ranging from black to white, are associated with increasing values of density) allows to visualise the most relevant internal features of the sample. Hence, black and/or very dark portions of the micrographs are correlated with less dense materials (air, water or ice), while white speckles correspond to denser components (i. e. denser inclusions and/or minerals). The ceramic matrix is therefore identifiable as dark grey colour, while the quartz grain temper is dispersed in it, visible as lighter grey inclusions. The lighter chemical composition and the diffused porosity (about 40\%) are responsible for the lighter density of the matrix when compared to the quartz grains [37,38]. Quartz grains, angular and sub-angular in shape, appear particularly abundant in the coronal section. In the transversal and sagittal sections, the quartz grains are mostly visible at the centre of the images, along the $x$-axis and the $z$-axis of the transversal and sagittal section, respectively. These zones of temper clustering correspond to the cross-cutting planes between the coronal and the other two sections. The preferential orientation of the quartz grain temper is related to the briquettes' manufacture procedure: because of the uniaxial pressing of the mixture, the temper grains orientate with their major axis perpendicular to the stress direction (i.e. laying on the coronal section). 


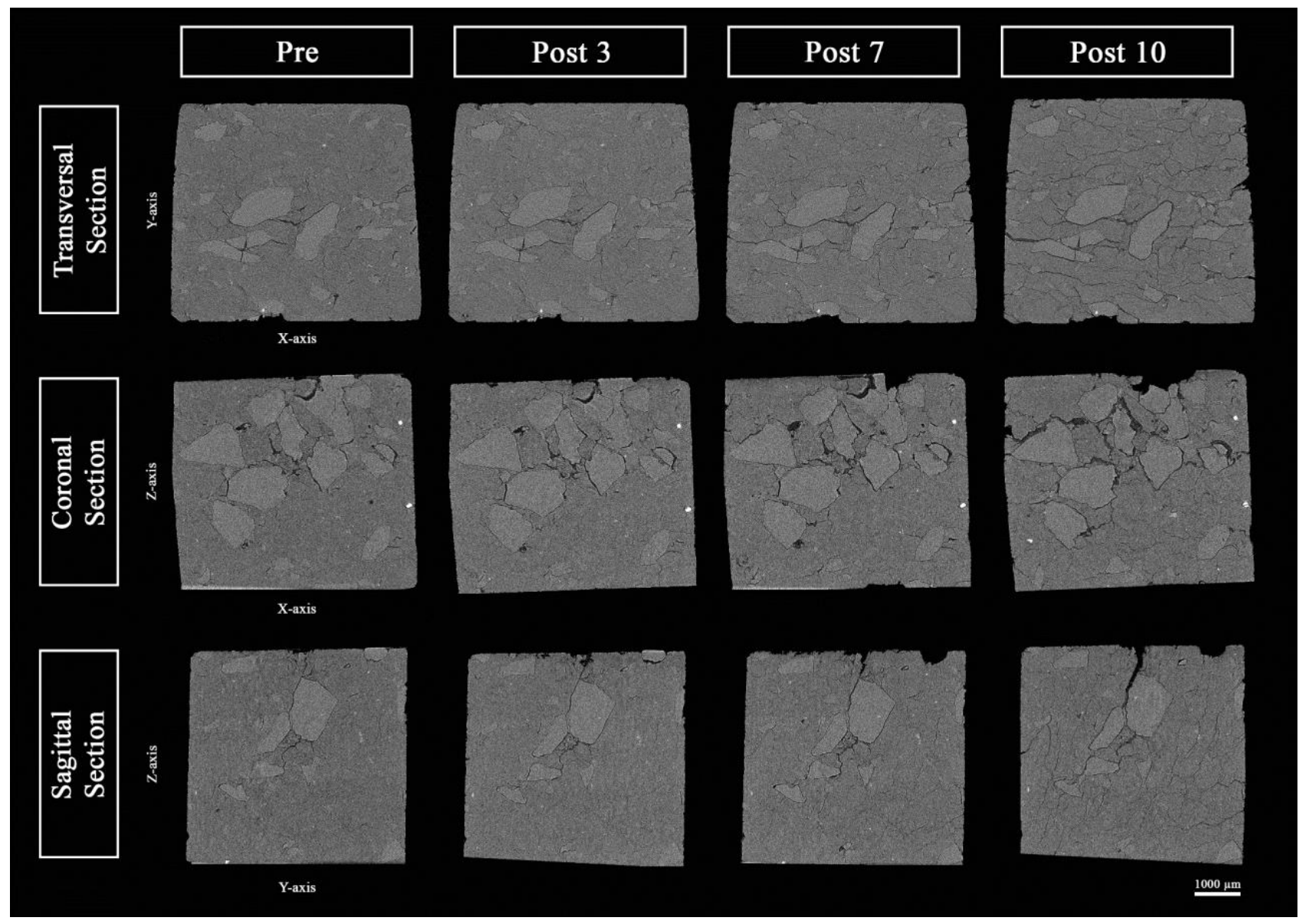

Figure 2 Overview of the three orthogonal sections captioned from the micro-CT.

For both the untreated and treated samples, the blank and dark-grey features visible in micrographs (Figure 2) correspond to air or ice inside pores, fissures and fractures. In particular, fractures surrounding the quartz grain boundaries are associated with the $\alpha-\beta$ quartz phase transition, occurring during the firing of the ceramic (at around $573{ }^{\circ} \mathrm{C}$ ), with a volume expansion [39]. In fact, such phase transition is reversible, and causes a detachment surface between the quartz grain and the matrix once the ceramic cools down after firing. Finally, small bright spots, particularly visible in the coronal section, can be associated with denser minerals (i.e. rutile, anatase, iron oxides).

The micro-CT technique is very effective when studying pre vs. post-treatment structural modifications and requires the 3D registration of the different scans for facilitating the comparison. The high-resolution micrographs in Fig. 1 are perfectly comparable and show that the number of fractures increases as the freeze-thaw treatment is repeated. In particular for transversal and coronal sections, it can be noticed that the fractures around the quartz grains gradually migrate through the ceramic body, reaching the surface of the briquette in the Post 10 micrographs. Moreover, at the upper edge of the coronal section, a detachment of a temper fragment at the Post 7 stage occurs. It is clear, particularly from the Post 7 and Post 10 Coronal sections (Figure 2), that quartz grain-boundaries serve as major discontinuities for the localisation and propagation of fractures. This is also visible in the sagittal section, where another phenomenon also becomes evident: superficial small fractures not detectable in the Pre-sample micrograph (in particular, in the upper-right edge of the sample) increase their size and length towards the inside of the sample, and stop when they reach a quartz grain. Such 
behaviour has been observed in other brittle materials, where inclusions (as well as pores) have the ability to stop the fracture propagation and improve the toughness of the ceramic [27, 40, 41].
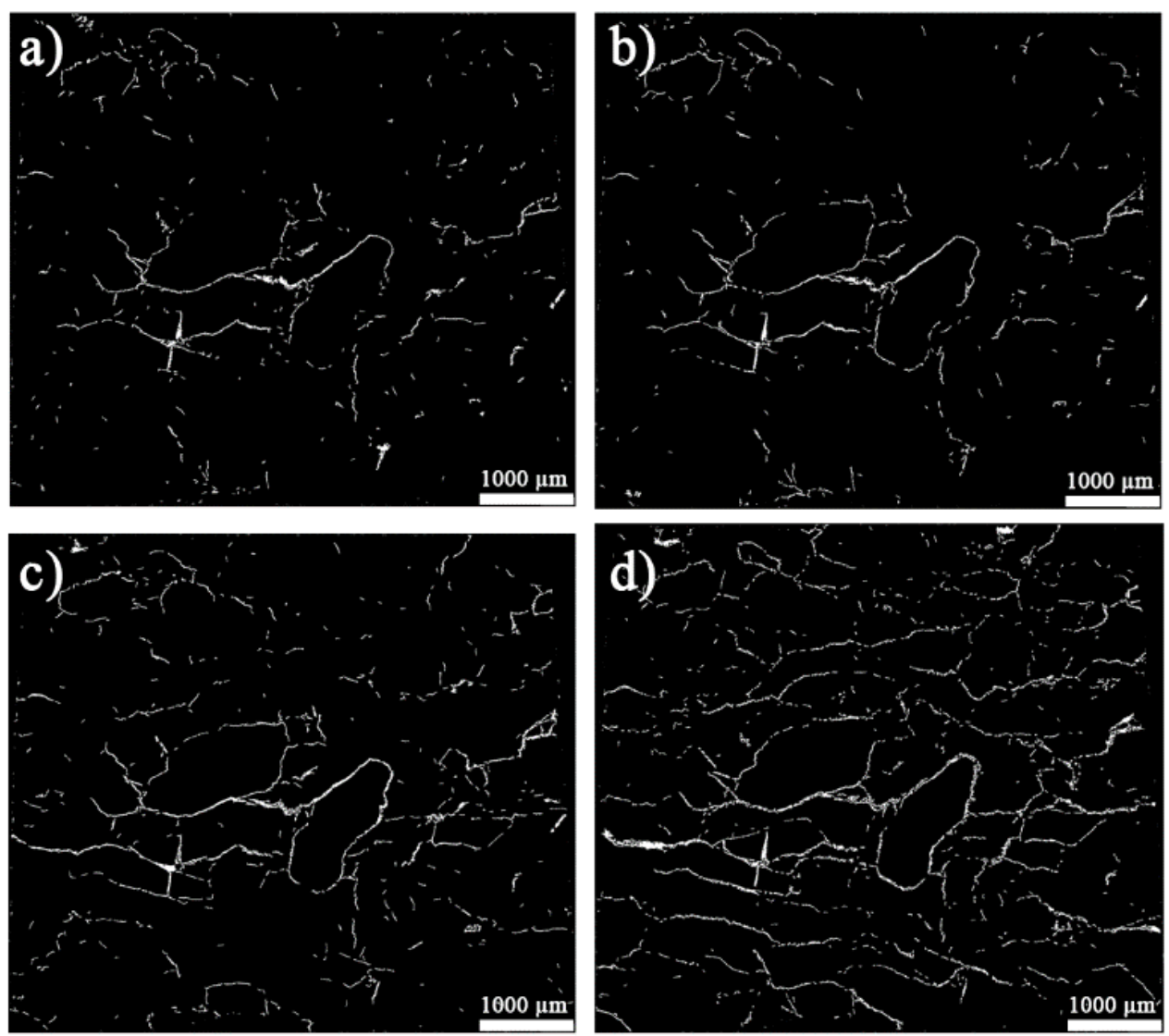

Figure 3 Segmentation of fractures via thresholding of the transversal section: a) Pre b) Post 3 c) Post 7 d) Post 10.

The fracture network segmentation was performed on micro-CT micrographs via thresholding (Figure 3). For each of the selected sections, we calculated fracture area (F) and the relative percentage of fracture $(\% \mathrm{~F})$ (Table 1$)$. F values increase from Pre- to Post10 sample, in all three investigated planes. In particular, the coronal section shows the highest value of $\%$ F moving from the Pre- $(2.8 \%)$ to the Post10 stage $(5.1 \%)$. Such high values can be associated with higher concentrations of the quartz temper and to the formation of wider fractures in this section (as compared to transversal and sagittal sections), created by ice expansion during the freeze-thawing steps.

\begin{tabular}{|c|c|c|c|c|c|c|c|c|c|c|c|c|}
\hline & \multicolumn{4}{|c|}{ Transversal Section } & \multicolumn{4}{|c|}{ Coronal Section } & \multicolumn{4}{|c|}{ Sagittal Section } \\
\hline & Pre & Post3 & Post7 & Post10 & Pre & Post3 & Post7 & Post10 & Pre & Post3 & Post7 & Post10 \\
\hline ROI Area $\left(\mathrm{mm}^{2}\right)$ & 27.85 & 27.99 & 28.17 & 28.82 & 27.2 & 26.91 & 27.05 & 27.11 & 24.72 & 24.37 & 24.77 & 25.16 \\
\hline Fracture Area $\left(\mathrm{mm}^{2}\right)$ & 0.44 & 0.44 & 0.7 & 1.1 & 0.77 & 0.8 & 1.09 & 1.37 & 0.4 & 0.43 & 0.55 & 0.73 \\
\hline Fracture Area (\%) & 1.6 & 1.6 & 2.5 & 3.8 & 2.8 & 3 & 4 & 5.1 & 1.6 & 1.8 & 2.2 & 2.9 \\
\hline
\end{tabular}

Table 1 Fracture area evolution over the freeze-thaw cycles. ROI Area: overall surface of the selected section (region of interest); Fracture Area (F): total fracture surface as obtained via thresholding of the selected section; Fracture Area $(\% \mathrm{~F})$ : fracture surface relative percentage. 


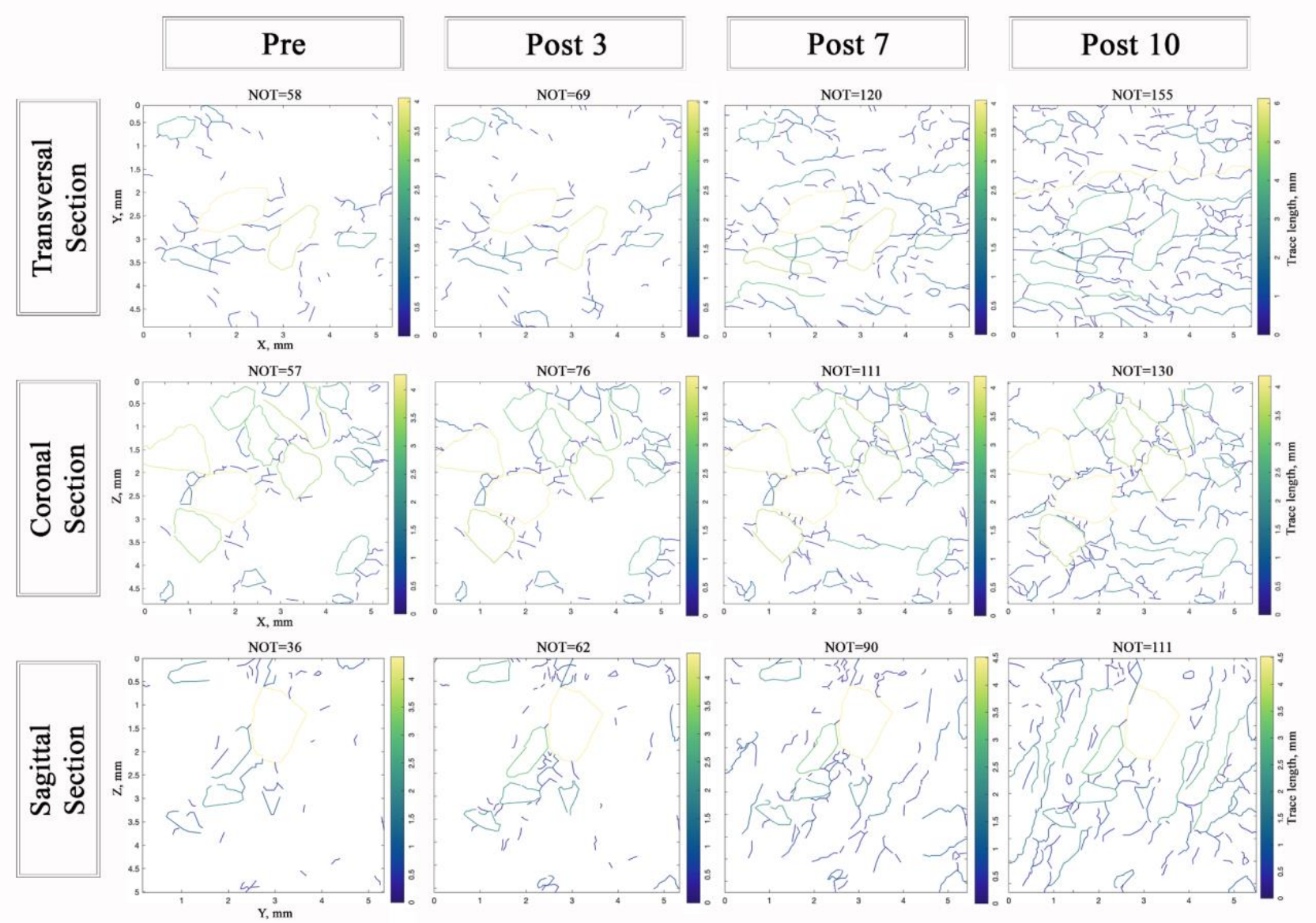

Figure 4 Maps of fracture trace length. Colour-coded based on fracture length (as reported in the scale bars). The number of traces (NOT) is reported above each map.

\subsection{FracPaQ fracture network analysis after freeze-thaw testing}

\subsubsection{Fracture length}

Figure 4 shows trace length maps obtained analysing the selected sections of the Pre, Post 3, Post 7 and Post 10 cycles with FracPaQ. The colour of the fractures moves from blue to yellow with increasing length. For all three sections at the Pre stage, most of the fractures correspond to the quartz grain-boundaries and are the longest fractures at this stage, exceeding $4 \mathrm{~mm}$ (Figure 4).

These features are particularly visible in the coronal section where the uneven distribution of quartz - grains creates a large cluster of stiff material towards the top edge of the sample. On the other hand, fractures within the matrix are scarce and mostly concentrate near the quartz grains. These fractures mostly fall in the range between $0.5-1.0 \mathrm{~mm}$ (Figure 5). 
a)

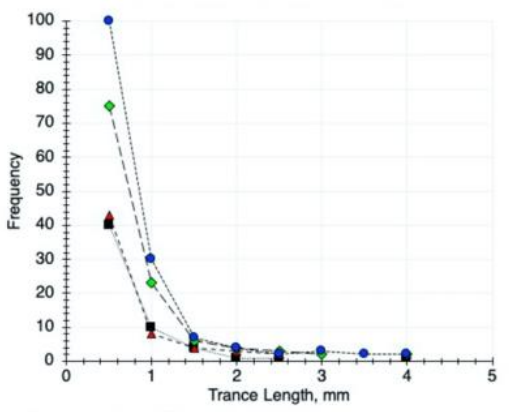

b)

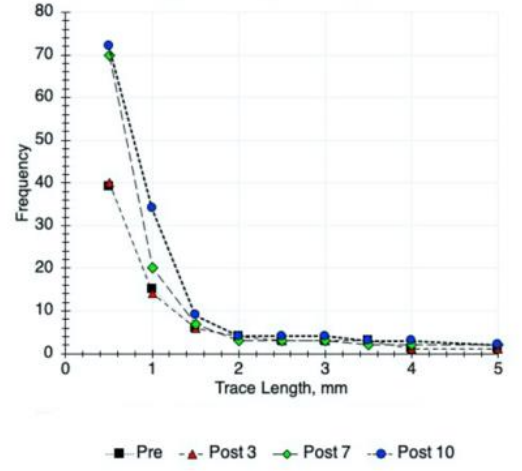

c)

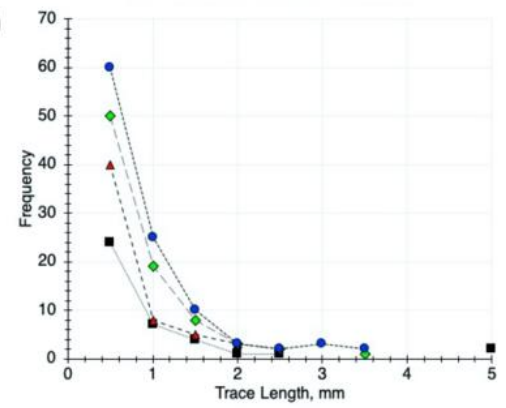

Figure 5 Frequency distribution of fracture lengths for the three sections: a) Transversal; b) Coronal; c) Sagittal. Samples deriving from different freeze-thaw cycles are represented with different symbols and colours. Markers plot the number of fractures for a specific class, with binning every $0.5 \mathrm{~mm}$.

Overall, the number of fracture traces increases with each freeze-thaw cycle (Table 2), although the increase is more prominent after the Post 3 stage (Figure 4). Figure 5 shows that, in all sections, the increase in the number of small fractures (less than $1 \mathrm{~mm}$ ) is significantly higher than the increase in the number of longer fractures (more than $1 \mathrm{~mm}$ ). These results indicate that, while some of the preexisting fractures lengthen, the newly formed fractures remain small in comparison to the pre-existing grain boundary fractures.

Looking in more detail at the increase in the number of fractures in each section (Table 2), we observe that the transversal and coronal sections experience the highest increase in fracture numbers between the Post 3 and Post 7 stages. Differently, the sagittal section shows the highest increase in fracture numbers between the Pre and Post 3 stages. This behaviour is most likely related to the detachment of temper grains, visible through comparison of the Pre and Post 3 sagittal sections in Figure 2 and Figure 4.

Fracture length gradually increases during the treatment, and its effect is particularly noticeable in the Post 10 stage, where fractures cutting almost the entire sample can be observed in the transversal and sagittal sections (Figure 4). This phenomenon can be explained by a widespread coalescence of smaller fractures that must have happened between the seventh and the tenth treatment cycle. This interpretation is also supported by the increase in the number of fractures longer than $1 \mathrm{~mm}$ (Figure $5)$.

\begin{tabular}{|l|l|l|l|l|l|l|l|l|l|l|l|l|}
\hline & \multicolumn{4}{|l|}{ Transversal Section } & \multicolumn{2}{l|}{ Coronal Section } & \multicolumn{3}{l|}{ Sagittal Section } \\
\cline { 2 - 16 } & Pre & Post3 & Post7 & Post10 & Pre & Post3 & Post7 & Post10 & Pre & Post3 & Post7 & Post10 \\
\hline Number of Traces (NOT) & 58 & 64 & 117 & 153 & 57 & 76 & 111 & 130 & 35 & 58 & 85 & 107 \\
\hline Variation in the NOT (\%) & - & 8 & 90 & 38 & - & 33 & 46 & 17 & - & 66 & 47 & 26 \\
\hline Number of Segments (NOS) & 212 & 245 & 491 & 796 & 438 & 555 & 729 & 917 & 137 & 248 & 392 & 666 \\
\hline Variation in the NOS (\%) & - & 17 & 95 & 49 & - & 27 & 31 & 26 & - & 81 & 58 & 70 \\
\hline Intensity (segment/mm) & 1.3 & 1.4 & 2.6 & 3.6 & 2.1 & 2.3 & 2.9 & 3.4 & 0.9 & 1.3 & 1.8 & 2.7 \\
\hline Variation in Intensity (\%) & - & 8 & 90 & 38 & - & 6 & 25 & 19 & - & 44 & 38 & 50 \\
\hline Density (segment/mm 2 $^{2}$ & 8.3 & 9.7 & 18.9 & 28.3 & 17.2 & 20.9 & 27.5 & 34.6 & 5.3 & 9.6 & 13.7 & 23.2 \\
\hline Variation in Density (\%) & - & 17 & 95 & 49 & - & 22 & 32 & 26 & - & 81 & 43 & 70 \\
\hline
\end{tabular}

Table 2. Overview of the variation for number of fracture traces and segments, and for fracture intensity and density in the three sections. Differences in values compared to the previous freezethaw cycle are reported as percentage of variation $(\%)$ for each parameter in table. 


\subsubsection{Intensity and density of fractures}

In all sections at Pre stage, fracture intensity and fracture density maps (Figure 6 and Figure 7, respectively) show higher values (green and yellow portions) mainly at the centre of the sample. The comparison of these maps with the micro-CT micrographs (Figure 2) immediately shows that high values in intensity and density correspond to the grain-boundary fractures.

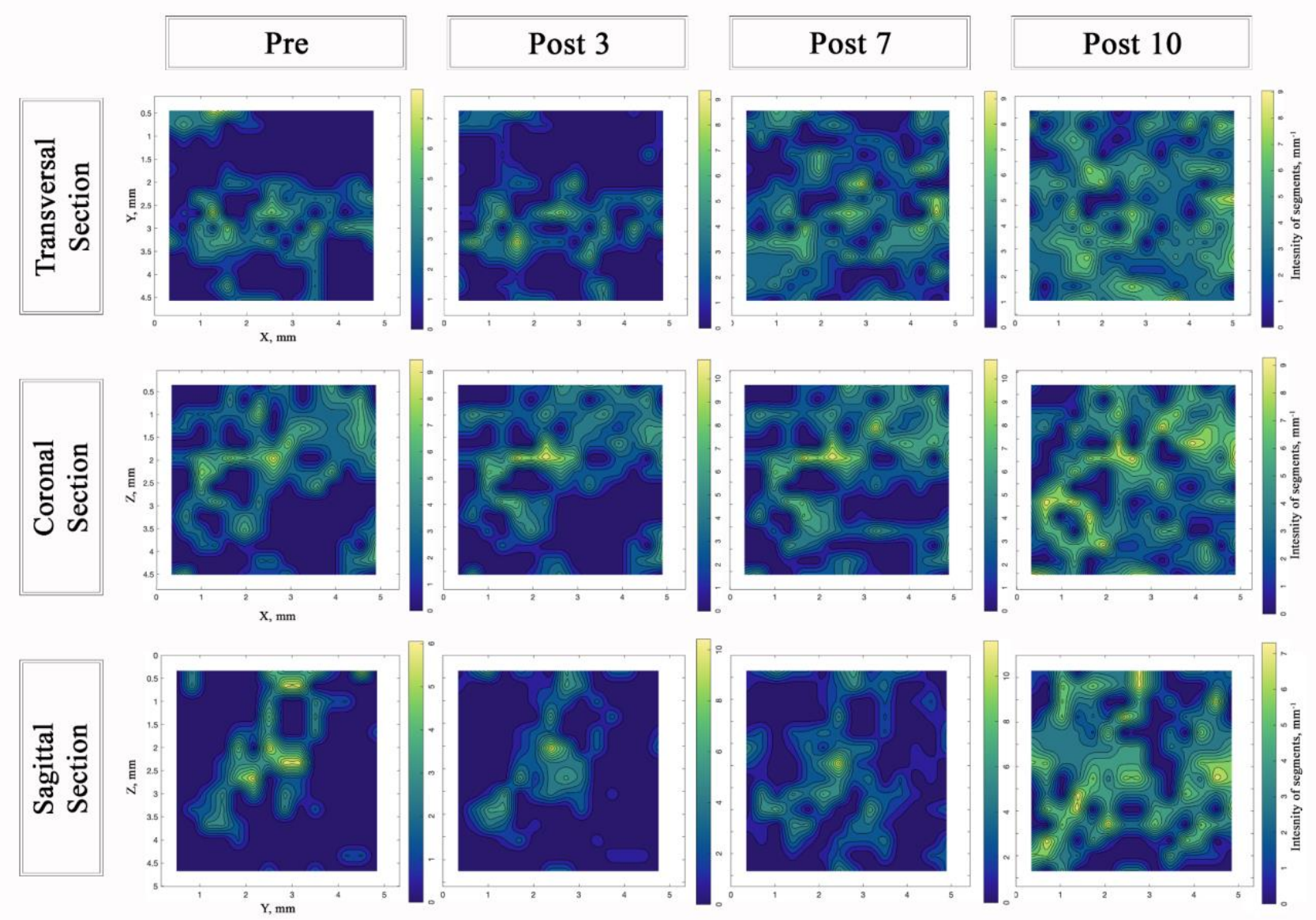

Figure 6 Fracture intensity maps. Brighter colours correspond to higher fracture intensity.

We observe an overall increase in the values of fracture intensity and density during the freeze-thaw cycles (Table 2). In particular, after the first 3 freeze-thaw cycles, areas of high intensity and density are still mostly confined to the central portions of the sections, highlighting the grain-boundary fractures. When comparing the variation in the average intensity and density values between the Pre and the Post 3 across the different sections (Table 2), the transversal and coronal sections show a relatively small change (increments of $8-10 \%$ and $17-22 \%$ respectively), while in the sagittal section variations are more marked (increment of 44 and $81 \%$, respectively).

Variations occurring between the third and the seventh freeze-thaw cycle are mostly evident in the transversal and sagittal sections, with average intensity and density values for the transversal section that nearly double moving from Post 3 to Post 7 (Table 2). From the fracture intensity maps, it emerges that, after repeated freeze-thaw cycles, fractures are distributed anisotropically within the sample: in the sagittal section, the alignment has a clear inclined spread (Post 7, Figure 6), while in 
the transversal section the broadening appears horizontal. It is not coincidentally that these preferential directions, which also mark the quartz grain orientation distribution, correspond to the cross-cutting planes with the coronal section. When comparing the Post 7 and the Post 10 intensity maps (Figure 6) a further propagation of the fractures throughout the whole ceramic is observed. Bright areas broaden and create fracture 'corridors' that connect the inner portions of the sample with its edges. This transition is consistent with the stage of fracture length extension and coalescence described for the fracture trace maps (Figure 4).

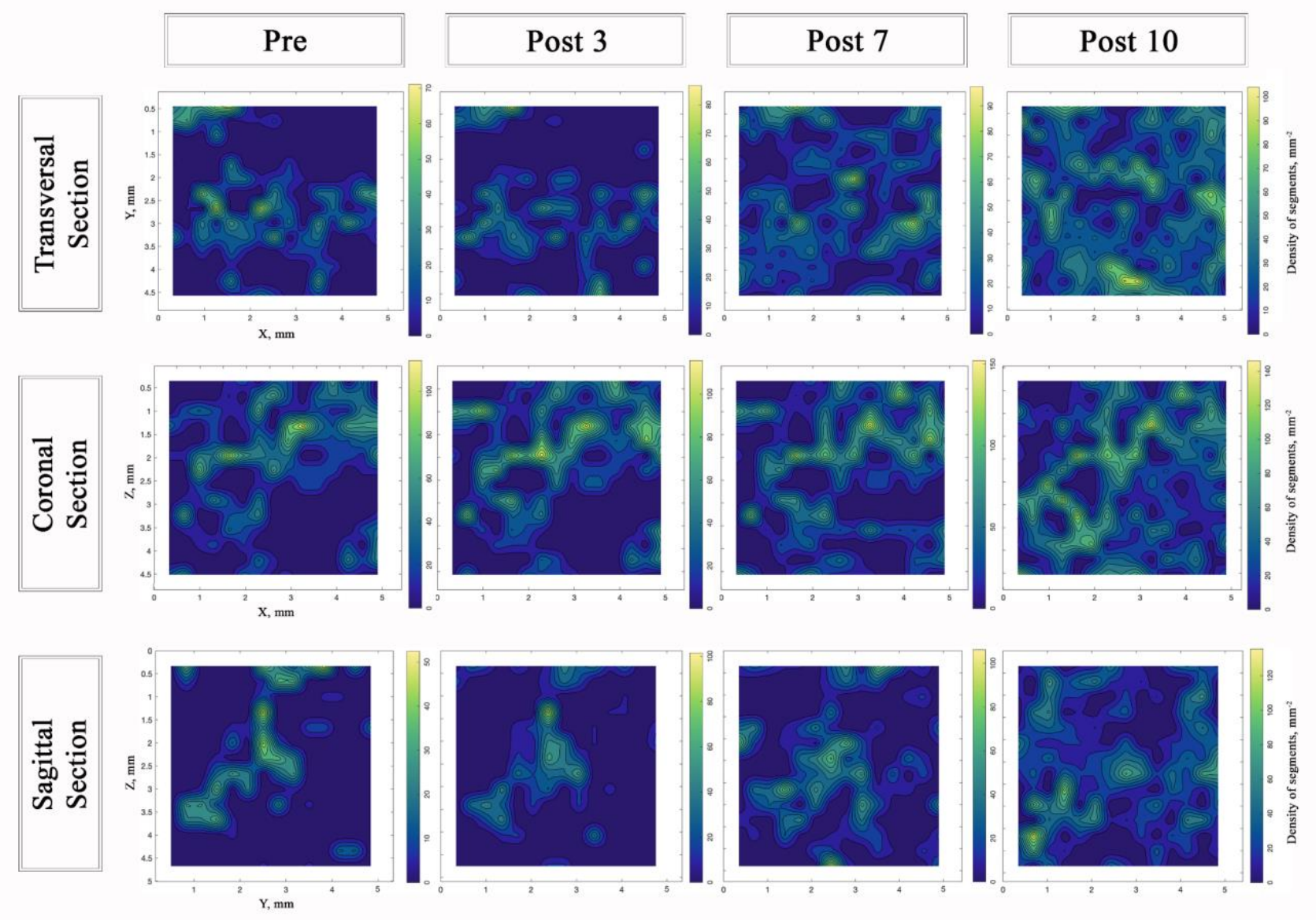

Figure 7 Fracture density maps. Brighter colours correspond to higher fracture density.

Similarly to intensity maps, density maps (Figure 7) show that as the deformation advances fractures tend to create clusters within the ceramic matrix that from the inner portion (compare Post 3 and Post 7, Figure 7) moves and grow towards the edges of the ceramic material. In particular, for the coronal section, density reaches the highest values (Post 7 and Post 10), although the areas with higher fracture density remain concentrated around the quartz grains. For the other two sections, it seems that in Post 10 (Figure 7) the density clusters have moved to the edge of the sample. 


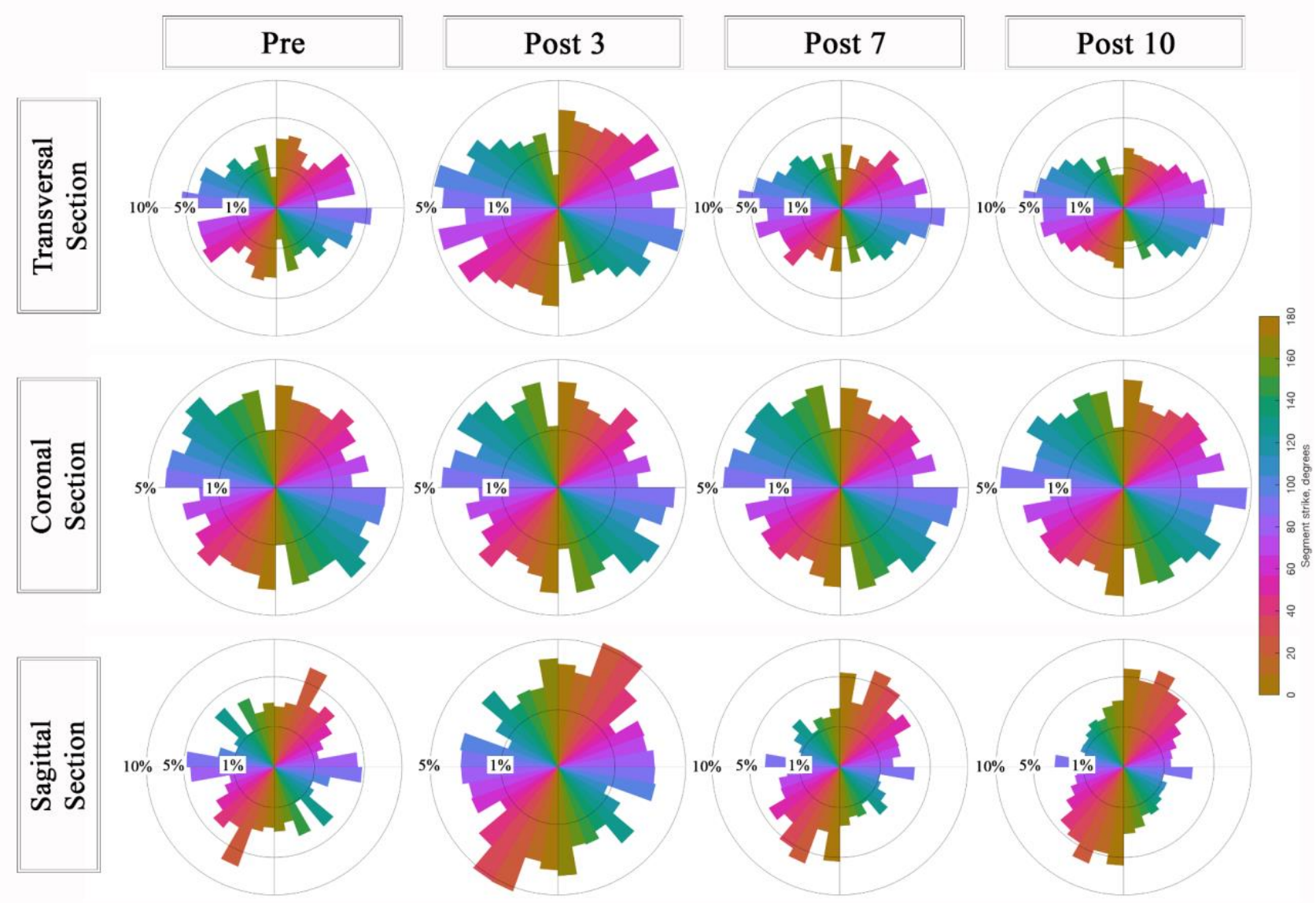

Figure 8 Rose diagrams visualising the variations in fracture trends with freeze-thaw cycles.

\subsubsection{Orientation of fractures}

Variations in fracture orientation have been visualised using rose plots (Figure 8). This data visualisation can help to assess fracture abundance as a function of their orientation [26]. The rose plots in Figure 8 show variations with number of cycles (from Pre- to Post 10) as well as between the three orthogonal sections (from Pre- to Post 10). In particular, in the transversal sections, fractures tend to strike preferentially in a horizontal direction (along the $\mathrm{x}$-axis). This preferential distribution becomes more evident with increasing freeze-thaw cycles, and at final stage of deformation almost the totality of fractures distributes within $80^{\circ}$ and $100^{\circ}$ from the vertical (Figure 8). Similarly, in the sagittal sections, fractures show a preferential alignment which becomes increasingly consistent with the number of freeze-thaw cycles. When comparing the rose diagram for these sections with the maps of trace length and density, it becomes evident that is the original orientation of the quartz grains (and therefore of the grain-boundary fractures) that guides the development of fractures. This is well captured by the rose diagram of the Sagittal Pre-treatment section, where the most prominent petal of the rose plot inclined at $30^{\circ}$ from the vertical correspond to the orientation of the quartz grainboundary fractures (Figure 4). Conversely, the rose plots for the coronal section do not show any preferential fracture orientation (Figure 8). This observation can be directly related to the presence of the large quartz grains and, therefore, to the high number grain-boundary fractures whose segments orient isotropically around the temper grains. 
a)
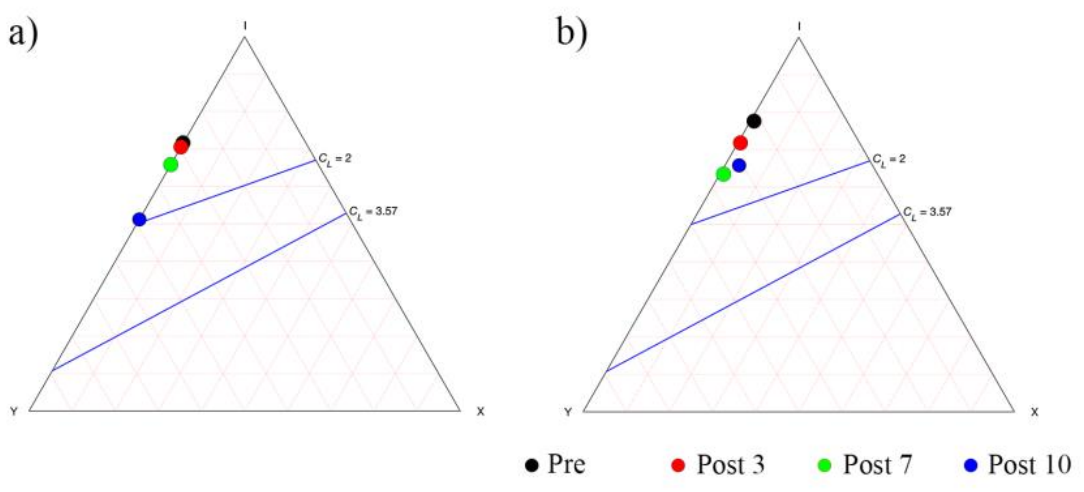

c)

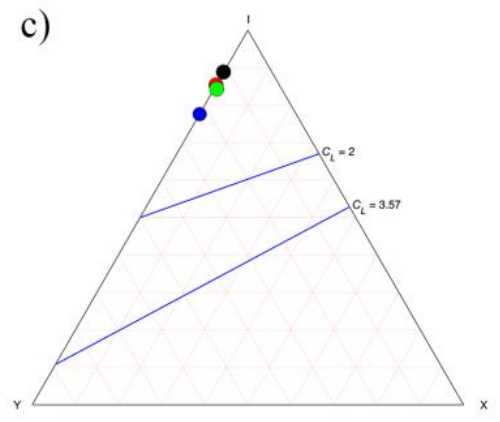

Figure 9 Ternary plots of fracture connectivity for the fracture pattern in the Transversal (a), Coronal (b), and Sagittal (c) sections showing the progression in fracture connectivity in the three orthogonal sections for increasing number of freeze-thaw cycles. Two contour lines for Connections per line (CL) are also shown, using indicative values as described by Sanderson \& Nixon [42].

\subsubsection{Fracture connectivity}

The anisotropy given by the alignment of quartz grains, also determines the evolution of fracture connectivity within the sample, as observed in the three sections. In Figure 9, the connectivity evolution with the application of freeze-thaw cycles is drawn for each section. In the triangular diagrams (Figure 9), $C_{L}$, indicates the number of connections per line: this parameter can be used as a measure of connectivity of a fracture network. Particularly interesting are specific values of $\mathrm{C}_{\mathrm{L}}$ which 'contour' the IYX ternary diagram: any network of fractures that lies above the line $\mathrm{C}_{\mathrm{L}}=2$ is considered disconnected, irrespectively of its density; whereas connectivity values lying below the $\mathrm{C}_{\mathrm{L}}=3.57$ represent fully connected networks. If fracture network connectivity falls in the region bounded by $2 \leq \mathrm{C}_{\mathrm{L}}<3.57$, it is indicative of a network whose fractures are connected in clusters, however these clusters are not connected [36].

In our case study, the connectivity plots (Figure 9) show increase in connectivity with the application of freeze-thaw cycles. In all three sections, a similar trend of fracture network development can be observed: (i) the Pre stage show low connectivity (i.e. more I-nodes than Y- or X-nodes) resulting in low connectivity ratios; (ii) then, moving towards the tenth cycle, more Y-nodes form. Even if freezethawing improves the connectivity of the fractures, all the fracture networks over the 10 cycles remain in the region above the $C_{L}=2$ contour, meaning that the networks are not fully connected. The Post 10 transversal section measures the highest value of network connectivity with a value close to the $\mathrm{C}_{\mathrm{L}}=2$ contour.

The increase of the connectivity between fractures also cause the improvement of the ability of the fracture network to carry fluid flow. Although the threshold of two connections per line $\left(\mathrm{C}_{\mathrm{L}}=2\right.$ line in Figure 9) is never crossed, the overall proportion of Y-nodes (particularly within the fracture corridors highlighted by the intensity and density maps in Figures 6 and 7, respectively), suggests that moving from the Pre- to the Post 10 cycle, fractures are likely to be linked and form continuous pathways through the ceramic material. 


\section{Summary and Implications}

It has been generally observed that during brittle deformation of materials pre-existing flaws act to concentrate stresses thereby acting as the loci for the initiation and propagation of cracks and fractures $[9,43,44]$. In this studied case the main discontinuities are represented by the grain-boundary fractures related to volume contraction ( $\beta$ to $\alpha$ phase transition) of the quartz grains after firing of the ceramic. The influence of the quartz temper shape and size has already been proven to affect the mechanical properties of the material and the propagation of the fractures within a ceramic body [45, 46]. Additionally, in terms of mechanical properties of the material, the presence of pre-existing fractures (and the temper itself), while reducing the strength of the material, can improve its toughness [9].

Quantitative results produced by FracPaQ on selected micro-CT micrographs provided insights on the dynamic of the fracture network created under repeated freeze-thaw cycles. Fracture length maps allowed us to visually and quantitatively measure fracture growth between cycles. Together with these data, comparisons of the variation of intensity and density values offer a criterion for interpreting fracture evolution during the freeze-thaw treatment. Considering that intensity expresses the measure of fracture segments' length per area, while density measures the number of fracture segments in an area, it was observed that the percentages of variation for these two parameters are coupled over the whole experiment: meaning a simultaneous lengthening of existing fractures and formation of new fractures. This observation was interpreted as evidence that new fractures formed by branching off existing fractures. This interpretation is also consistent with the data obtained for network connectivity, which showed that the connectivity of fractures in the ceramic sample was achieved via Y-nodes. From the length, intensity and density maps, it could be also deduced that most of the damage was accumulated between the third (Post 3) and seventh (Post 7) cycle of the treatment. In this interval FracPaQ registered the highest percentage of variation in all these three parameters (Table 2 and Figures 4, 6 and 7). Overall, micro-CT imaging and FracPaQ outputs show that the presence of pre-existing (i.e. pre-treatment) grain-boundary fractures, together with the size and the distribution of quartz grains within the samples, exerts a critical influence on the evolution of the fracture network in the ceramic material. Moreover, the anisotropic distribution of the quartz grains along the coronal section directly affected the direction of fracture propagation (Figure 10).
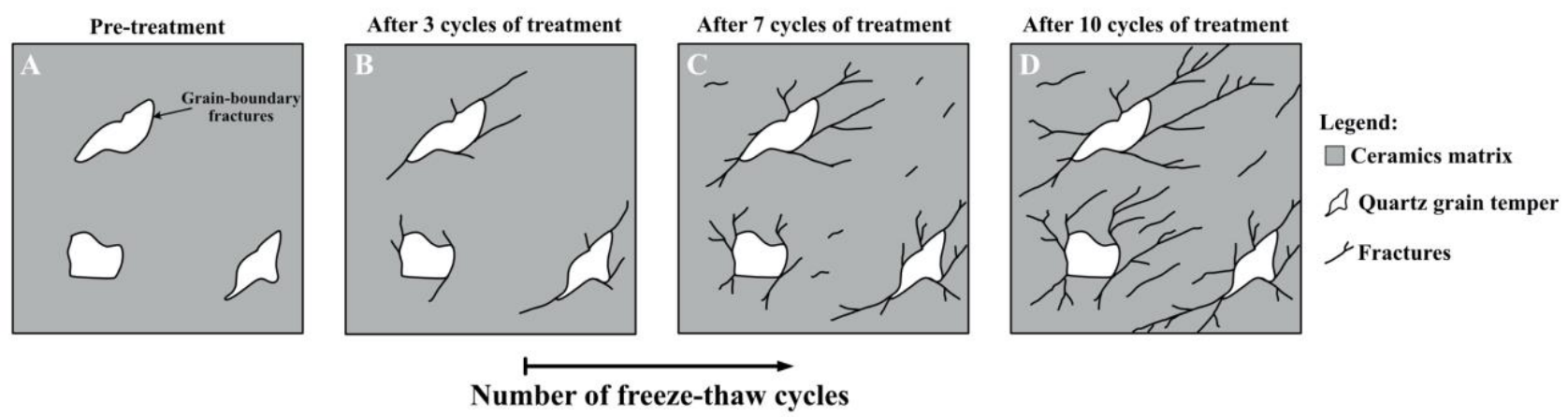

Number of freeze-thaw cycles

Figure 10 Cartoon showing the evolution of fractures within the ceramic sample and the role exerted by the temper grains in the initiation and propagation of fractures.

In conclusion, a new methodology that combines micro-CT tomographic imaging and advanced image analysis is presented in this paper. Importantly, the combination of micro-CT and cooling rotating stage allowed to analyse continuously the same sample over many cycles of freeze-thawing. The main advantage of this approach relies on the ability to dynamically study the deformation pattern within the same sample over time. The versatility of the presented method renders it applicable to 
many fields in environmental and material sciences for the analysis of fracturing in man-made and natural materials, such as concrete, soils and rocks.

\section{CRediT authorship contribution statement}

Carlo Porfido: Conceptualization, Methodology, Investigation, Writing - original draft, Visualization. Roberto Emanuele Rizzo: Methodology, Investigation, Writing - original draft, Visualization. David Healy: Writing - review \& editing. Matteo Spagnuolo: Writing - review \& editing, Resources. Roberto Terzano: Writing - review \& editing, Resources. Ignazio Allegretta: Investigation, Writing - original draft, Supervision.

\section{References}

[1] N. Matsuoka, J. Murton, Frost Weathering: Recent Advances and Future Directions, Permafr. Periglac. Process. 19 (2008) 195-210. https://doi.org/10.1002/ppp.620.

[2] M. Pigeon, J. Marchand, R. Pleau, Frost resistant concrete, Constr. Build. Mater. 10 (1996) 339-348. https://doi.org/10.1016/0950-0618(95)00067-4.

[3] J. Ruedrich, D. Kirchner, S. Siegesmund, Physical weathering of building stones induced by freeze-thaw action: A laboratory long-term study, Environ. Earth Sci. 63 (2011) 1573-1586. https://doi.org/10.1007/s12665-010-0826-6.

[4] R. Prikryl, B.J. Smith, Building Stone Decay: From Diagnosis to Conservation, Special Pu, Geological Society, London, 2007. https://doi.org/10.1017/CBO9781107415324.004.

[5] D.H. Everett, The thermodynamics of frost damage to porous solids, Trans. Faraday Soc. 57 (1961) 1541-1551. https://doi.org/10.1039/TF9615701541.

[6] J. Walder, B. Hallet, Theoretical Model of the Fracture of Rock During Freezing., Bull. Geol. Soc. Am. 96 (1985) 336-346. https://doi.org/10.1130/0016-7606(1985)96<336:atmotf>2.0.co;2.

[7] J.S. Walder, B. Hallet, The physical basis of frost weathering: toward a more fundamental and unified perspective., Arct. Alp. Res. 18 (1986) 27-32. https://doi.org/10.2307/1551211.

[8] G.W. Scherer, Crystallization in pores, Cem. Concr. Res. 29 (1999) 1347-1358. https://doi.org/10.1016/S0008-8846(99)00002-2.

[9] C.B. Carter, M.G. Norton, Ceramic materials: Science and engineering, 2013. https://doi.org/10.1007/978-1-4614-3523-5.

[10] N.S. Müller, G. Vekinis, P.M. Day, V. Kilikoglou, The influence of microstructure and texture on the mechanical properties of rock tempered archaeological ceramics, J. Eur. Ceram. Soc. 35 (2015) 831-843. https://doi.org/10.1016/j.jeurceramsoc.2014.09.025.

[11] J. Zhao, W. Li, H. Luo, J. Miao, Research on protection of the architectural glazed ceramics in the Palace Museum, Beijing, J. Cult. Herit. 11 (2010) 279-287. https://doi.org/10.1016/j.culher.2009.05.004. 
[12] V. Ducman, A.S. Škapin, M. Radeka, J. Ranogajec, Frost resistance of clay roofing tiles: Case study, Ceram. Int. 37 (2011) 85-91. https://doi.org/10.1016/j.ceramint.2010.08.012.

[13] J. Malaiškiene, R. Mačiulaitis, Frost resistant ceramics produced from local raw materials and wastes, Procedia Eng. 57 (2013) 739-745. https://doi.org/10.1016/j.proeng.2013.04.093.

[14] G. Pia, M.L. Gualtieri, L. Casnedi, P. Meloni, F. Delogu, C. Siligardi, Microstructural evolution in porous ceramics subjected to freezing-thawing cycles: Modelling experimental outcomes, Ceram. Int. 44 (2018) 16992-16998. https://doi.org/10.1016/j.ceramint.2018.06.141.

[15] Z. Yang, W. Weiss, J. Olek, Interaction between Micro-Cracking, Cracking, and Reduced Durability of Concrete: Developing Methods for Considering Cumulative Damage in Life-Cycle Modeling, (2005). https://doi.org/10.5703/1288284313255.

[16] T. Suzuki, T. Shiotani, M. Ohtsu, Evaluation of cracking damage in freeze-thawed concrete using acoustic emission and X-ray CT image, Constr. Build. Mater. 136 (2017) 619-626. https://doi.org/10.1016/j.conbuildmat.2016.09.013.

[17] F. Liu, Z. You, X. Yang, H. Wang, Macro-micro degradation process of fly ash concrete under alternation of freeze-thaw cycles subjected to sulfate and carbonation, Constr. Build. Mater. 181 (2018) 369-380. https://doi.org/10.1016/j.conbuildmat.2018.06.037.

[18] Y. Shields, E. Garboczi, J. Weiss, Y. Farnam, Freeze-thaw crack determination in cementitious materials using 3D X-ray computed tomography and acoustic emission, Cem. Concr. Compos. 89 (2018) 120-129. https://doi.org/10.1016/j.cemconcomp.2018.03.004.

[19] V. Cnudde, M.N. Boone, High-resolution X-ray computed tomography in geosciences: A review of the current technology and applications, Earth-Science Rev. 123 (2013) 1-17. https://doi.org/10.1016/j.earscirev.2013.04.003.

[20] T. De Kock, M.A. Boone, T. De Schryver, J. Van Stappen, H. Derluyn, B. Masschaele, G. De Schutter, V. Cnudde, A pore-scale study of fracture dynamics in rock using X-ray micro-CT under ambient freeze-thaw cycling, Environ. Sci. Technol. 49 (2015). https://doi.org/10.1021/es505738d.

[21] W. Tian, N. Han, Pore characteristics $(>0.1 \mathrm{~mm})$ of non-air entrained concrete destroyed by freeze-thaw cycles based on CT scanning and 3D printing, Cold Reg. Sci. Technol. 151 (2018) 314322. https://doi.org/10.1016/j.coldregions.2018.03.027.

[22] V. Mazars, O. Caty, G. Couégnat, A. Bouterf, S. Roux, S. Denneulin, J. Pailhès, G.L. Vignoles, Damage investigation and modeling of 3D woven ceramic matrix composites from X-ray tomography in-situ tensile tests, Acta Mater. $140 \quad$ (2017) 130-139. https://doi.org/10.1016/j.actamat.2017.08.034.

[23] S.C. Wu, T.Q. Xiao, P.J. Withers, The imaging of failure in structural materials by synchrotron radiation X-ray microtomography, Eng. Fract. Mech. 182 (2017) 127-156. https://doi.org/10.1016/j.engfracmech.2017.07.027.

[24] A. Murru, D.M. Freire-Lista, R. Fort, M.J. Varas-Muriel, P. Meloni, Evaluation of postthermal shock effects in Carrara marble and Santa Caterina di Pittinuri limestone, Constr. Build. Mater. 186 (2018) 1200-1211. https://doi.org/10.1016/j.conbuildmat.2018.08.034. 
[25] G.S. Senesi, I. Allegretta, C. Porfido, O. De Pascale, R. Terzano, Application of micro X-ray fluorescence and micro computed tomography to the study of laser cleaning efficiency on limestone monuments covered by black crusts, Talanta. $178 \quad$ (2018) 419-425. https://doi.org/10.1016/j.talanta.2017.09.048.

[26] D. Healy, R.E. Rizzo, D.G. Cornwell, N.J.C. Farrell, H. Watkins, N.E. Timms, E. GomezRivas, M. Smith, FracPaQ: A MATLABTM toolbox for the quantification of fracture patterns, J. Struct. Geol. 95 (2017) 1-16. https://doi.org/10.1016/j.jsg.2016.12.003.

[27] I. Allegretta, G. Eramo, D. Pinto, V. Kilikoglou, Strength of kaolinite-based ceramics: Comparison between limestone- and quartz-tempered bodies, Appl. Clay Sci. 116-117 (2015) 220230. https://doi.org/10.1016/j.clay.2015.03.018.

[28] P.M. Rice, On the origins of pottery, J. Archaeol. Method Theory. 6 (1999). https://doi.org/10.1023/A:1022924709609.

[29] X. Wu, C. Zhang, P. Goldberg, D. Cohen, Y. Pan, T. Arpin, O. Bar-Yosef, Early pottery at 20,000 years ago in Xianrendong Cave, China, Science (80-. ). 336 (2012) 1696-1700. https://doi.org/10.1126/science.1218643.

[30] B. Andrews, J. Roberts, Z. Shipton, S. Bigi, M. Chiara Tartarello, G. Johnson, How do we see fractures? Quantifying subjective bias in fracture data collection, Solid Earth. 10 (2019) 487-516. https://doi.org/10.5194/se-10-487-2019.

[31] L. Griffiths, M.J. Heap, P. Baud, J. Schmittbuhl, Quantification of microcrack characteristics and implications for stiffness and strength of granite, Int. J. Rock Mech. Min. Sci. 100 (2017) 138150. https://doi.org/10.1016/j.ijrmms.2017.10.013.

[32] R.E. Rizzo, D. Healy, M.J. Heap, N.J. Farrell, Detecting the Onset of Strain Localization Using Two-Dimensional Wavelet Analysis on Sandstone Deformed at Different Effective Pressures, J. Geophys. Res. Solid Earth. 123 (2018) 10,460-10,478. https://doi.org/10.1029/2018JB015898.

[33] M. Mauldon, W.M. Dunne, M.B. Rohrbaugh, Circular scanlines and circular windows: New tools for characterizing the geometry of fracture traces, J. Struct. Geol. 23 (2001) 247-258. https://doi.org/10.1016/S0191-8141(00)00094-8.

[34] J.B. Rohrbaugh, W.M. Dunne, M. Mauldon, Estimating fracture trace intensity, density, and mean length using circular scan lines and windows, Am. Assoc. Pet. Geol. Bull. 86 (2002). https://doi.org/10.1306/61eede0e-173e-11d7-8645000102c1865d.

[35] C. Zeeb, E. Gomez-Rivas, P.D. Bons, P. Blum, Evaluation of Sampling methods for fracture network characterization using Outcrops, Am. Assoc. Pet. Geol. Bull. 97 (2013) 1545-1566. https://doi.org/10.1306/02131312042.

[36] T. Manzocchi, The connectivity of two-dimensional networks of spatially correlated fractures, Water Resour. Res. 38 (2002) 1-1-1-20. https://doi.org/10.1029/2000wr000180.

[37] I. Allegretta, G. Eramo, D. Pinto, A. Hein, The effect of temper on the thermal conductivity of traditional ceramics: Nature, percentage and granulometry, Thermochim. Acta. 581 (2014) 100109. https://doi.org/10.1016/j.tca.2014.02.024. 
[38] I. Allegretta, D. Pinto, G. Eramo, Effects of grain size on the reactivity of limestone temper in a kaolinitic clay, Appl. Clay Sci. 126 (2016) 223-234. https://doi.org/10.1016/j.clay.2016.03.020.

[39] A. De Noni, D. Hotza, V.C. Soler, E.S. Vilches, Analysis of the development of microscopic residual stresses on quartz particles in porcelain tile, J. Eur. Ceram. Soc. 28 (2008) 2629-2637. https://doi.org/10.1016/j.jeurceramsoc.2008.04.009.

[40] V. Kilikoglou, G. Vekinis, Y. Maniatis, Toughening of ceramic earthenwares by quartz inclusions: An ancient art revisited, Acta Metall. Mater. 43 (1995) 2959-2965. https://doi.org/10.1016/0956-7151(95)00006-H.

[41] V. Kilikoglou, G. Vekinis, Y. Maniatis, P.M. Day, Mechanical performance of quartztempered ceramics: Part I, strength and toughness, Archaeometry. 40 (1998) 261-279. https://doi.org/10.1111/j.1475-4754.1998.tb00837.x.

[42] D.J. Sanderson, C.W. Nixon, The use of topology in fracture network characterization, J. Struct. Geol. 72 (2015) 55-66. https://doi.org/10.1016/j.jsg.2015.01.005.

[43] W.D. Kingery, Introduction to Ceramics, J. Electrochem. Soc. 124 (1977). https://doi.org/10.1149/1.2133296.

[44] B.R. Lawn, N.P. Padture, L.M. Braun, S.J. Bennison, Model for Toughness Curves in TwoPhase Ceramics: I, Basic Fracture Mechanics, J. Am. Ceram. Soc. 76 (1993) 2235-2240. https://doi.org/10.1111/j.1151-2916.1993.tb07759.x.

[45] N.S. Müller, V. Kilikoglou, P.M. Day, G. Vekinis, The influence of temper shape on the mechanical properties of archaeological ceramics, J. Eur. Ceram. Soc. 30 (2010) 2457-2465. https://doi.org/10.1016/j.jeurceramsoc.2010.04.039.

[46] J.L. Amorós, M.J. Orts, S. Mestre, J. Garcia-Ten, C. Feliu, Porous single-fired wall tile bodies: Influence of quartz particle size on tile properties, J. Eur. Ceram. Soc. 30 (2010) 17-28. https://doi.org/10.1016/j.jeurceramsoc.2009.08.001 